\title{
Drug-Induced Bronchospasm - A Negligible Phenomenon?
}

\author{
J. Christian Virchow \\ Abteilung Pneumologie, Medizinische Universitätsklinik, Freiburg, Deutschland
}

Drug-induced side effects are a very common medical problem. Their prevalence has not been systematically assessed, but there are reports of approximately $2 \%$ adverse reactions among hospitalized patients [1]. Among all adverse reactions to drugs which lead to only mild symptoms and which are successfully treated by simply withdrawing the drug in question, a differentiation between pathophysiologically and psychopathologically induced symptoms is often difficult. In addition, in an individual patient, it may be difficult to discern side effects which can lead to discontinuation of certain medications from effects directly related to the desired effects of the drug or from symptoms caused by the disease intended to be treated. Furthermore, although not formally investigated, true or presumed adverse reactions to medical treatments are more likely to lead to non-compliant discontinuation of medical therapies than to any formal registration in doctor practises or central registries.

Although many adverse reactions are often attributed to hypersensitivity reactions, their true occurrence is most likely much less frequent. Drug-induced bronchospastic reactions for example are even less prevalent although potentially severe and life-threatening. Until now, there has been no formal analysis of the frequency and severity of drug-induced bronchospastic reactions. In this issue of Respiration Leuppi et al. [2] report data derived from a central Swiss Drug Monitoring Center from which they analyzed reported drug-induced episodes of bronchospasms and tried to evaluate predisposing risk factors.
Interestingly, among all adverse reactions to drugs reported to this registry, approximately $2 \%$ were considered to be bronchospastic, suggesting that at least $0.04 \%$ of all drug-induced side effects involved bronchospasms. This certainly underestimates the true incidence of druginduced bronchospastic reactions since there is most likely a selective overreporting of serious bronchospastic reactions or vice versa an underreporting of mild and moderate reactions. Furthermore, drugs known to cause bronchospastic reactions, such as $\beta$-blockers in patients with asthma, are likely to be missed in this series. Although the authors indirectly associate bronchospasm with asthmatic bronchospastic reactions, the precise pathogenetic mechanisms leading to the individual reactions remain unclear. Since left-ventricular failure due to $\beta$-receptor antagonists or ACE inhibitors may for example cause bronchospastic symptoms, which are clinically very similar to asthmatic bronchoconstriction, some doubts remain whether all bronchospastic reactions reported were indeed caused by asthma-like bronchoconstriction. Nevertheless, this report is also an interesting addendum to the rather ample literature on drug-induced asthma.

As might have been expected, non-steroidal antiinflammatory drugs such as metamizole most frequently caused bronchospastic reactions, 3 of which were fatal. These results underscore the clinical importance of analgesic intolerance and the so-called aspirin-sensitive asthma and the fact that this peculiar, relatively rare, idiosyncratic reaction is still insufficiently diagnosed or its

\begin{tabular}{ll}
\hline KARGER & ( $2001 \mathrm{~S}$. Karger AG, Basel \\
0025-7931/01/0684-0343\$17.50/0 \\
$\begin{array}{l}\text { Eax+4161306 1234 } \\
\text { www.karger.com }\end{array}$ & $\begin{array}{l}\text { Accessible online at: } \\
\text { www.karger.com/journals/res }\end{array}$
\end{tabular}

Dr. med. J. Christian Virchow
Abteilung Pneumologie, Medizinische Universitätsklinik
Universitätsklinikum Freiburg, Kilianstrasse 5
D-79106 Freiburg
Tel.+49761270 3731, Fax +49 761270 3704, E-Mail virchow@med1.ukl.uni-freiburg.de 
importance in causing life-threatening asthmatic reactions underestimated. This disturbing result calls for increased efforts to identify patients at risk and diagnose aspirin-sensitive asthma. Unfortunately, it has to be assumed that a number of reactions to over-the-counter NSAIDs were either not reported or their causal relationship remained unrecognized. In descending order of frequency, anti-infective drugs, medications used to treat cardiovascular disorders, exipients, parenteral administration of foreign protein (vaccines/immunoglobulins), colloids, hormones, (parenteral) application of glucocorticosteroids and other drugs are now reported. Of those it is noteworthy that glucocorticosteroids which are used to treat bronchospasms and hypersensitivity reactions can cause anaphylactic reactions and life-threatening bronchospasm [3]. The work by Leuppi et al. [2] reiterates that most drugs commonly used can induce bronchospastic reactions. Although their overall occurrence is relatively rare, physicians should be aware of these potential side effects and should be trained to take appropriate measures should these reactions occur.

References

1 Classen DC, Pestotnik SL, Evans RS, Burke JP: Computerized surveillance of adverse drug events in hospital patients. JAMA 1991;266: 2847-2851.

2 Leuppi JD, Schnyder P, Hartmann K, Reinhart WH, Kuhn M: Drug-induced bronchospasm: Analysis of 187 spontaneously reported cases. Respiration 2001;68:345-351.

3 Kamm GL, Hagmeyer KO: Allergic-type reactions to corticosteroids. Ann Pharmacother 1999;33:451-460. 